\title{
STATIC BALANCE OF PERSONS WITH INTELLECTUAL DISABILITIES, VISUAL IMPAIRMENT AND WITHOUT DISABILITIES
}

\author{
Aija Klavina, Ph.D.*, Ilze Jekabsone \\ Academy of Sport Education of Latvia
}

*Corresponding author: Aija Klavina, Department of Physiotherapy, Sport Medicine and Adapted Physical Activity, Latvian Academy of Sport Education, Brivibas tr. 333, Riga, Latvia. Email: aija.klavina@gmail.com

\begin{abstract}
This study aimed to compare static balance of students with severe intellectual disabilities (SID), visual impairment (VI) and non-disabled (ND) persons 18-24 years of age. Eleven students with VI, nine with SID and eleven ND students performed the One-Leg Stance balance test (10s). The Digital Balance Analyzer (DBA) platform was used to measure the Balance Index (range from 0 "excellent balance" to 10 "very poor balance"). Subjects performed tests in open and closed eyes conditions. On right leg with open eyes results indicated statistically significant differences between both groups of students with disabilities and nondisabled students $(\mathrm{p}<.05)$, while results between groups of students with disabilities were not significantly different. The mean scores on the left leg with open eyes were not significantly different among the three groups $(\mathrm{p}>.05)$. In tests on both legs with closed eyes significant difference was in mean results for students with VI $(\mathrm{p}<.05)$, while no differences were found for students with and without SID $(\mathrm{p}>.05)$. The main finding of this study was that static balance scores were inferior in VI group than in SID and ND group. Finally, all participants demonstrated significantly better static balance skills on right leg than on left leg.
\end{abstract}

Key Words: Static balance, visual impairment, intellectual disability

The balance skills are critical for the acquisition of the postural control and motor skills (Massion, 1992). The dynamic interaction between sensory and motor components is fundamental characteristic of postural control. Moreover, sensory information is crucial to assess and control the body position and movements in space. The motor strategies used to maintain balance and postural control are associated with the ability to accurately perceive the environment through peripheral sensory systems and to centrally process and integrate proprioceptive, visual and vestibular inputs at the level of the central nervous system (CNS) (Kubilay, Yildrim, Kara, \& Akdur, 2011). In addition, the individual needs ability to control the relation between the center of mass (COM) and the person's base of support to maintain balance against perturbation. Successful performance of balance indicates that all forces and torques acting on the body are in equilibrium and the person's COM is within their limits of stability (Gagnon, Swaine, \& Friedman, 2004; Jover, Schmitz, \& Centelles, 2010).
Besides, the balance performance is dependent on the quality of the CNS and the mood and motivation of the individuals (Hatzitaki, Zisi, \& Kollias, 2002; Hands \& Larkin, 2006).

In persons with intellectual disabilities (ID) or deviation of the CNS limits the motor development, including balance skills. The accuracy of sensory feedback is related to maturation level of specific neural connections that controls performance of a certain skill. Limitations in CNS functioning results in poor body image and reduced activity in individuals with ID (Hatzitaki et al., 2002; Hands et al., 2006). For example, Volman, Visser \& LensveltMulders (2007) found that persons with ID have delayed and more variability in reaction times than persons without ID. Other studies have indicated that postural control skills are lower for persons with ID comparing to those without ID (Block, 1991; Hale, Miller, Barach, \& Gray, 2009; Henderson, 1985; Vuillerme, Marin \& Debu, 2001). Lahtinen, Rintala, and Malin (2007), presenting 30-year longitudinal study 
on physical skills of individuals with intellectual disabilities, found that in adolescence only $25 \%$ of the participants $(n=77)$ were able to complete a static balance task (e.g., one leg stance for 60 $\mathrm{s}$, i.e., stork stand test) while in adulthood (n $=74$ ) the total of those who could perform the task dropped to less than $10 \%$. They concluded that intellectual development have significant impact on balance skills. Persons with severe intellectual disabilities (SID) have even higher risk of frequent falls (Hale, Bray, \& Littman, 2006; Shumway-Cook \& Woollacott, 1985) with incidence rates increasing progressively by ageing (Carmel, Bar-Chad, Lotan, Merrick, \& Colleman, 2003). Although, it is known that participants with intellectual disabilities had abnormal pattern of walking, delayed motor responses to postural perturbations (Carvalho \& Almeida, 2009), the research on static balance in persons with SID has been minimal.

Visual impairment (VI) is associated with limitations in postural control and is an important factor in falls (Lord \& Menz, 2000) and related injuries (Anand, Buckley, Scally, \& Elliott, 2003; Aydog, Aydog, Cakci, \& Doral, 2006). Persons with VI must rely on somatosensory and vestibular information to maintain postural stability and adjust to body positions in space to compensate for restrictions in visual systems (Anand et al., 2003; Friedrich, Grein, Wicher, Schuetze, Mueller, Lauenroth, 2008; Horvat, Ray, Ramsey, Miszko, Keeney, \& Blasch, 2003). Studies comparing static and dynamic balance skills of VI and non-disabled persons have demonstrated that approximately $80 \%$ of an individual's sensory perception is gathered by the visual system (Friedrich et al., 2008), that initiates and integrates other sensory inputs to select a balancing strategy (Schmid, Nardone, De Nunzio, Schmid, \& Schieppati, 2007).

The previous research studies have investigated static balance skills by comparing individuals with and without VI (Giagazoglou, Amiridis, Zafeiridis, Thimara, Kouvelioti, \& Kellis, 2009), or persons with and without ID (Blomqvist, Olsson, \& Wallin, 2013; Dellavia, Pallavera, Orlando, \& Sforza, 2009; Hale, Miller, Barach, \& Gray, 2009; Vuillerme, Marin \&
Debu, 2001). While static balance appears to be affected in both groups, for individuals with VI and with ID, the relationship between equilibrium components in different population groups has not been fully explored in the literature, particularly regarding single-leg stances and tasks with eyes opened compared with eyes closed.

This study aimed to compare static balance of persons with severe intellectual disabilities, visual impairment and non-disabled persons 18 24 years of age.

\section{METHODS}

Eleven persons with visual impairment (VI), nine persons with severe intellectual disabilities (SID) and eleven non-disabled (ND) persons participated in the study. The group of VI included five males and five females with a mean age $19 \pm .3$ years (range $18-21$ years), mean height of $166.3 \pm 8.3 \mathrm{~cm}$ (range $155-179 \mathrm{~cm}$ ), and mean body mass of $69.4 \pm 7.8 \mathrm{~kg}$ (range $50-84 \mathrm{~kg}$ ). All participants were recruited from the special school for students with visual impairment. While none of the participants was blind, they had moderate to severe visual impairment (the visual acuity was $20 / 70$ or less). While none of the participants participated in regular sports or physical activities, they attended PE class in special school for 40 minutes two times per week. The group of SID included seven males and one female with a mean age $22 \pm .8$ years (range $19-25$ years), mean height of $174.6 \pm 11.5 \mathrm{~cm}$ (range $157-187 \mathrm{~cm}$ ), mean body mass of $72.1 \pm 8.9 \mathrm{~kg}$ (range $60-86 \mathrm{~kg}$ ). All participants were recruited from the special institute for persons with intellectual disabilities. All had been defined as having severe intellectual disability and they have attended special class for students with SID in special schools for students with intellectual disabilities. The institute offered their clients optional 60 minutes physical activity program one to two times per week. However, the administration of the center did not provide information on involvement of selected participants in this program. The group of nondisabled persons included four males and six females with a mean age $20 \pm .5$ years (range 18 
-24 years), mean height of $176.3 \pm 4.0 \mathrm{~cm}$ (range $167-189 \mathrm{~cm})$, mean body mass of $70.8 \pm 11.4 \mathrm{~kg}$ (range $59-87 \mathrm{~kg}$ ). All non-disabled participants were undergraduate students in physiotherapy, recreation and physical education. None of the involved students participated in regular sports. No significant differences between the groups were found. The exclusion criteria for the three groups in current study were as follows: using any orthopaedic assistive device for walking, diagnosis of cerebral palsy, any sensory loss of function, stretch reflexes or strength in lower extremities that might impact the balance ability, current or past medical diagnosis of injury affecting balance within the last three years, medications affecting the central nervous system or known to affect balance or coordination, and current symptoms of dizziness or lightheadedness. Because of large variety in type and severity of disability as well as difference in number of each gender representatives in the three groups, the results were obtained and analyzed for males and females together within each subgroup.

\section{Instrument.}

The Digital Balance Analyzer (DBA) platform was used to measure the Balance Index (BI) (range from 0 "excellent balance" to 10 "very poor balance"). Platform was connected to the computer program DBA-Ruler for data recording and analyses. The equipment has been demonstrated to have good reliability and reproducibility (ICC 0.53 to 0.81 ) (Liepina, 2011).

\section{Data Collection.}

Subjects performed the balance test in the four conditions: 1) on the right leg with eyes open; 2) on the right leg with eyes closed; 3) on the left leg with eyes open; and 4) on the left leg with eyes closed. The subject was instructed to step on the balance platform with one leg, keep the non-test leg in a position of $90^{\circ}$ of hip flexion and $90^{\circ}$ of knee flexion. Two ten-second trials were recorded for each leg, with a ten-second rest between each trial. All tests were performed by the same evaluator and standardized in terms of positioning and testing. Participants took part in the study after their scheduled classes in the school or institution.

\section{Data Analyses.}

Results are reported as mean \pm SEM. Differences between the three groups with regard to the balance index were compared using Kruskal - Wallis Test for nonparametric variables and one-way ANOVA for parametric variables. Data analysis was performed using SPSS version 20.0 for Windows. Statistical significance was set at $\mathrm{p}<.05$.

\section{RESULTS}

In the balance test on right leg with open eyes mean results of the Balance Index (BI) indicated no significant differences between the two groups of students with disabilities $(\mathrm{M}=1.78 \pm .27$ for VI, $\mathrm{M}=1.56 \pm .18$ for SID, $\mathrm{p}>.05$ ), while the mean result of non-disabled students $(\mathrm{M}=.75$ $\pm .08)$ was significantly higher than for students with disabilities $(\mathrm{p}<.05)$ (Figure 1).

\section{Figure 1}

Mean scores of the Balance Index in stance on right leg (VI - visual impairment, SID - severe intellectual disability, ND - non-disabled)

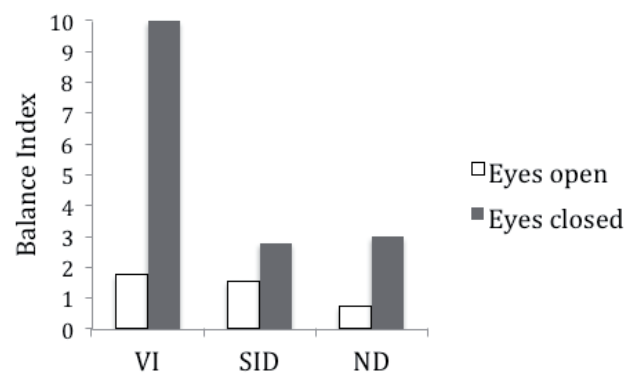

In the test when standing on right leg with closed eyes all persons with VI could not keep the balance without touching plate with other leg for the required period of time (10 seconds). Figure 1 illustrates that the mean score of BI for this group was $10.00 \pm .00$ that was significantly lower than for the two other groups $(\mathrm{p}<.05)$. The mean BI of persons with SID in this position was $2.87 \pm .47$ and 
for non-disabled students $3.00 \pm .30$. The difference in mean scores between persons with SID and non - disabled persons was not significantly different ( $p$ $>.05$ ) (Figure 1). Analyses of results within groups indicated significant differences in BI mean results between stance on the right and left leg for students with VI and non-disabled students $(\mathrm{p}<.05)$, while for young persons with SID no significant difference was found $(\mathrm{p}>.05)$.

In the test on left leg with open eyes the BI mean results were not significantly different between the three groups ( $\mathrm{M}=6.20 \pm 1.14$ for $\mathrm{VI}, \mathrm{M}=3.01 \pm 1.04$ for SID, $\mathrm{M}=3.90 \pm 1.20$ for ND, $\mathrm{p}>.05$ ) (Figure 2). Interestingly, that students with SID had slightly higher scores than students without disabilities.

\section{Figure 2}

Mean scores of the Balance Index in stance on left leg

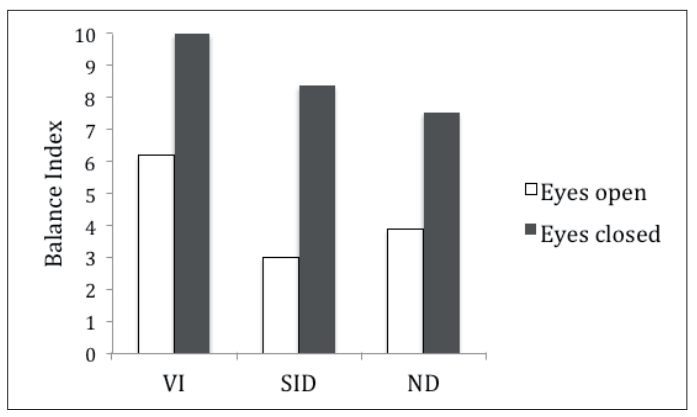

The BI mean scores on the left leg with closed eyes were similar to results on right leg with closed eyes. All ten participants with VI again demonstrated very low BI scores $(\mathrm{M}=10.00 \pm$ 8.61) that were significantly different from the group of non-disabled students $(\mathrm{M}=7.54 \pm .99$, $\mathrm{p}<.05)$ and persons with SID $(\mathrm{M}=8.37 \pm 1.09$, $\mathrm{p}<.05$ ) (Figure 2). The mean results between non-disabled students and persons with SID were not significantly different $(\mathrm{p}>.05)$. Within group analyses of results between stance on the left leg with open and closed eyes revealed no statistical differences for persons with VI $(p>.05)$, while for persons with SID and non-disabled persons mean results were significantly different $(\mathrm{p}<$ $.05)$.

Finally, comparing mean BI scores in test performance between stance on the right and left leg all results, but closed eyes for SVI and open eyes for students with SID, were significantly different $(p<.05)$ (Table 1.)

\section{Table 1}

Descriptive results of Balance Index

\begin{tabular}{|lccc|}
\hline & $\begin{array}{l}\text { Visual } \\
\text { Impairment }\end{array}$ & $\begin{array}{l}\text { Severe } \\
\text { Intellectual } \\
\text { Disability }\end{array}$ & $\begin{array}{l}\text { Non }- \\
\text { disabled }\end{array}$ \\
\hline $\begin{array}{l}\text { Eyes } \\
\text { open, } \\
\text { right leg } \\
( \pm \text { SEM })\end{array}$ & 1.78 & 1.56 & .75 \\
\hline $\begin{array}{l}\text { Eyes } \\
\text { closed, } \\
\text { right leg } \\
( \pm \text { SEM })\end{array}$ & 10.00 & \pm .18 & \pm .08 \\
\hline $\begin{array}{l}\text { Eyes } \\
\text { open, left }\end{array}$ & 6.20 & 3.8 & 3.00 \\
leg & \pm 1.14 & \pm 1.04 & \pm .30 \\
$( \pm$ SEM $)$ & & & \\
\hline $\begin{array}{l}\text { Eyes } \\
\text { closed, } \\
\text { left leg }( \pm\end{array}$ & 10.00 & 8.37 & 7.54 \\
SEM $)$ & \pm .94 & \pm 1.09 & \pm .99 \\
\hline
\end{tabular}

\section{DISCUSSION}

The group of students with visual impairment demonstrated lower scores in the four positions of static balance test than groups of students with severe intellectual disabilities and nondisabled students. These outcomes replicated other studies exploring difference of static balance parameters between low vision and able body persons (Giagazoglou, et al., 2009; Shmid et al., 2007; Loughran et.al., 2005). In recent study Tomomitsu and colleagues (2013) noted that currently only few studies have examined postural stability by comparing persons with and without visual impairment and we did not find studies comparing balance skills of persons with VI and indivduals with other types of disabilities, for example, severe intellectual disabilities. Furthermore, Tomomitsu and colleagues (2013) indicated that, although balance appears to be 
affected in individuals with visual impairment, the relationship between factors of visual and balance system has not been fully explored in the literature. Several studies have reported that balance skills of non-disabled persons worsened on one -leg stance with closed eyes (e.g., Hakkinen, Holopainen, Kautiainen, Sillanpaa, \& Hakkinen, 2006), indicating that visual system plays major role in maintaining balance (Lord, 2006; Hallemans, Orbitus, Meire, \& Aerts, 2010), and postural instability increases in absence of vision (Blomqvist et al., 2013; Giagazoglou et al., 2009). Interestingly that for participants in the four study groups Balance Index scores were higher on the right leg in both positions, with open and closed eyes, than on left leg. Few studies have described possible explanation for this finding. For example, Shmid et al. (2007) in their study discussed that such outcome might indicate that visual proprioceptive information is more sensitive than mechanical proprioceptive information from the vestibular and somatosensory systems. The proprioception inputs could be overloading the left leg, as previous studies have suggested that unilateral stance tasks might depend on some neuromuscular requirement (Hazime, Allard, Ide, Amorim, \& Tanaka, 2011) and muscular strength (Giagazoglou et al., 2009, Horvat et al., 2003; Shumway-Cook, \& Woollacott, 2003). The ability of the postural control system to select a higher joint configuration variance (Hsu, Scholz, Schoner, Jeka, \& Kiemel, 2007; Krishnamoorthy, Yang, \& Scholz, 2005) can contribute to the maintenance of postural stability by correcting lower extremity movements in individuals with vision impairments. However, Tomomitsu et al., (2013) in their recent study noted that very few studies have examined the postural control of persons with VI in a single-leg stance under different eye conditions. We have not found studies exploring physiological mechanisms of postural stability with open and closed eyes when standing on one leg for persons with severe intellectual disabilities.

In this study results of Balance Index scores for the group of persons with SID were significantly higher than for persons with
VI. Furthermore, in contrary to other studies reporting inferior balance skills for persons with ID than for non-disabled persons (Enkelaar, Smulders van Schrojenstein Lantman -de Valk, Geurts, \& Weerdesteyn, 2011; Hale, Miller, Barach, Skinner, \& Gray, 2009), in our study the mean Balance Index scores' differences between the two groups were not significantly different, except when standing on the right leg with eyes open where non-disabled persons had higher results. This might be explained by condition that there was physical exercise program provided one to two times per week for all clients with SID at the institution we conducted our study. However, we do not have information on how many, if any, balance exercises were included in the program. Many research studies have reported poor static balance scores for individuals with profound or severe disabilities (Lahtinen et al., 2007; Oppewal, Hilgenkamp, van Wijck, \& Evenhuis, 2013; Vuillerme, Marin, \& Debu, 2001), while the reasons for this have not yet been identified. For example, Halle, Bray and Littmann (2006) in their pilot study including nine persons with profound ID concluded that low motor control composite scores indicated a slowing of motor responses to postural perturbations explaining frequent falls in participants. In other study Carvalho and Almeida (2009) exploring balance skills in persons with Down syndrome found a proprioceptive deficit for this group. In addition, it is common that the lifestyle and health-related problems of individuals with SID also contribute to postural instability.

While this study did not investigate difference of static balance skills between the dominant and non-dominant leg, it should be considered for future research. The current findings in persons without disabilities reveal inconsistent results (Hoffman et al., 1998). For example, McCurdy and Langford (2006) did not find relationship between static balance on the dominant and non-dominant leg in healthy young people. In contrast, Ross and colleagues (2004) reported evidence that the dominant leg has better balance and proprioceptive function to control landing forces. However, no differences between contralateral limbs were demonstrated in 
medial-lateral sway and time to stabilize posture after landing (Ross et al., 2004). Hoffman et al. (1998) analyzed static postural sway and found no difference in performance between dominant and non-dominant leg.

\section{Conclusions}

The results of this study supported the findings of other studies reporting that persons with VI have poor static balance skills indicating that impairment of visual functions is associated with increased postural instability. The comparative data of Balance Index scores for persons with SID were not consistent with previous studies, however, these results can not be generalized because of the small sample size. In our study the Balance Index scores were similar to those of the persons without disabilities. Finally, for all the three study groups there was significant difference between Balance Index scores when standing on the right and left leg, demonstrating that balance on left leg was inferior than on the right one. Future research could focus on determining the causes of such differences.

There were several limitations in the study that should be noted. The primary limitation was the small sample selection in the three study groups. All participants were volunteers and necessarily representative of the larger population of the each target population. The test of the Balance Index was done only once in each research site. It is possible that the time, mood or health status of individuals could impact test performance. Future research might use repetitive measures to diminish impact of the external factors.

The results of this study underscore the importance of comparing physical skills in individuals with severe disabilities. Because we know very little about the nature of naturally occurring changes in this population, this study highlights the importance of exploring motor skill performance in both persons with and without disabilities

\section{REFERENCES}

Anand, V., Buckley, F. G., Scally, A., \& Elliott, D.B. (2003). Postural stability in the elderly during sensory pertubations and dual tasking: the influence of refractive blur. Investigative Ophthalmology and Visual Science, 44, 2885-9.

Aydog, E., Aydog, S. T., Cakci, A., Doral, M. N. (2006). Dynamic postural stability in blind athletes using the biodex stability system. International Journal of Sports Medicine, 27(5), 415-8.

Black, A. A., Wood, J.M., Lovie-Kitchin, J. E., \& Newman, B. M. (2008). Visual impairment and postural sway among older adults with glaucoma. Optometry and Vision Science, 85(6), 489-97.

Blomqvist, S., Olsson, J., \& Wallin, L. (2013) Adolescents with intellectual disability have reduced postural balance and muscle performance in trunk and lower limbs compared to peers without intellectual disability. Journal of Research in Developmental Disabilities, 34(1), 198-206.

Carmel, E., Bar-Chad, S., Lotan, M., Merrick, J. \& Colleman, R. (2003). Five Clinical Tests to Assess Balance Following Ball Exercises and Treadmill Training in Adult Persons With Intellectual Disability. The Journals of Gerontology, 58 (8), 767-772.

Carvalho, R. L., \& Almeida, G. L. (2009). Assessment of postural adjustments in persons with intellectual disability during balance on the seesaw. Journal of Intellectual Disability Research, 6.

Dellavia, C., Pallavera, A., Orlando, F., \& Sforza, C. (2009) Postural stability of athletes in special olympics. Perceptual and Motor Skills, 108, 608-622.

Enkelaar, L., Smulders E., van Schrojenstein Lantman -de Valk, H., Geurts, A. C. H., \& Weerdesteyn, V. (2011) A review of balance and gait capacities in relation to fall in persons with intellectual disabilities. Research in Developmental Disabilities, 33(1), 291-306. 
Friedrich, M., Grein, H. J., Wicher, C., Schuetze, J., Mueller, A., Lauenroth, A.

(2008). Influence of pathologic and simulated visual dysfunctions on thepostural system. Experimental Brain Research. 86(2), 305-14.

Gagnon, I., Swaine, B., Friedman, D. (2004) Children show decreased dynamicbalance after mild traumatic brain injury. Archives of Physical Medicine and Rehabilitation, 85, 444-452.

Giagazoglou, P., Amiridis, I. G., Zafeiridis, A., Thimara, M., Kouvelioti, V., \& Kellis, E. (2009). Static balance control and lower limb strength in blind and sighted women. European Journal of Applied Physiology, 107(5), 571-9.

Hakkinen, A., Holopainen, E., Kautiainen, H., Sillanpaa, E., \& Hakkinen, E. (2006). Neuromuscular function and balance prepubertal and pubertal blind and sighted boys. Acta Paediatrica, 95(10), 1277-83.

Hale, L., Bray, A., \& Littman, A. (2006). Assessing the balance capabilities of persons with profound intellectual disabilities who have experienced a fall. Journal of Intellectual Disability Research, 51(4), 260-268.

Hale, L., Bray, A., \& Littman, A. (2007). Assessing the balance capabilities of people with profound intellectual disabilities who have experience a fall. Journal of Intellectual Disability Research, 51(4), 260-268.

Hale, L., Miller, R., Barach, A., Skinner, M., \& Gray, A. (2009). Motor control test responses to balance perturbations in adults with an intellectual disability. Journal of intellectual and Developmental Disability, $34,81-86$.

Hallemans, A., Orbitus, E., Meire, F., \& Aerts, P. (2010). Low vision affects dynamic stability and gait. Gait \& Posture, 32(4), 547-551.

Hands, B., \& Larkin, D. (2006). Physical fitness differences in children with and without motor learning difficulties. European Journal of Special Needs Education, 21, 447-456.
Hatzitaki, V., Zisi, V., \& Kollias, I. (2002). Perceptual-motor contributions to static and dynamic balance control in children. Journal of Motor Behavior, 34, 161-170.

Hazime, F. A., Allard, P., Ide, M. R., Siqueira, C. M., Amorim, C.F., \& Tanaka, C. (2012) Postural control under visual and proprioceptive perturbations during double and single limb stance. Journal of Body Movement and Therapy. 16(2), 224-9.

Hoffman, M., Schrader, J., Applegate, T. \& Koceja, D. (1998). Unilateral postural control of the functionally dominant and nondominant extremities of healthy subjects. Journal of Athletic Training 33, 319-322.

Horvat, M., Ray, C., Ramsey, V., Miszko, T., Keeney, R., \& Blasch, B. (2003). Compensatory analysis and strategies for balance in individuals with visual impairments. Journal of Visual Impairment and Blind, 97, 695-703.

Hsu, W. L., Scholz, J. P., Schoner, G., Jeka, J. J., \& Kiemel, T. (2007) Control and estimation of posture during quiet stance depends on multijoint coordination. Journal of Neurophysiology, 97(4), 3024-35.

Jover, M., Schmitz, C., \& Centelles, L. (2010) Anticipatory postural adjustments in a bimanual load-lifting task in children with developmental coordination

disorder. Developmental Medicine and Child Neurology, 52, 850-855.

Krishnamoorthy, V., Yang, J. F., \& Scholz, J.P. (2005). Joint coordination during quiet stance: effects of vision. Experimental of Brain Research, 164(1), 1-17.

Kubilay, N. S., Yildrim, Y., Kara, B., \& Akdur, H. H. (2011). Effect of balancetraining and posture exercises on functional level in mental retardation. Fizyoterapi Rehabilitasyon, 22(2), 55-64.

Liepina, I. (2011). Promotion of balance abilities for sport climbers. Unpublished doctoral theses, Latvian academy of Sport Education.

Lord, S. R. (2006). Visual risk factors for falls in older people. Age and Ageing, 35(2), ii42ii45. 
Lord, S. R., \& Menz, H. B. (2000). Visual contributions to postural stability in older adults. Gerontology. 46, 306-10.

Loughran, S., Tennant, N., Kishore, A., \& Swan, I. R. (2005). Interobserver reliability in evaluating postural stability between clinicians and posturography. Clinical Otolaryngology. 30(3), 255-7.

Massion, J. (1992). Movement, posture and equilibrium: Interaction and coordination. Progress in Neurobiology, 38, 35-56.

Maurberg - de Castro, E., Lucenam C. S., Bruna, W. C., Boni, R. C., Campbell, D. F., \& Moares, R. (2010). Haptic Stabilization of Posture in Adults with Intellectual Disabilities Using Nonrigid Tool. Adapted Physical Activity Quarterly, 27, 208-225.

McCurdy, K., \& Langford, G. (2006). The relationship between maximum unilateral squat strength and balance in young adult men and women. Journal of Sports Science and Medicine, 5, 282-288.

Oppewal, A., Hilgenkamp, I. M. T., van Wijck, R., \& Evenhuis, H. M. (2013). Feasibility and outcomes of the Berg Balance Scale in older adults with intellectual disabilities. Research in Developmental Disabilities, 34(9), 2743-1752.

Ross, S., Guskiewicz, K., Prentice, W., Schneider, R.\& Yu, B. (2004). Comparison of biomechanical factors between the kicking and stance limbs. Journal of Sport Rehabilitation 13, 135-150

Schmid, M., Nardone, A., De Nunzio, A. M., Schmid, M., \& Schieppati, M. (2007). Equilibrium during static and dynamic tasks in blind subjects: no evidence of crossmodal plasticity. Brain, 130 (8), 2097-107.

Sforza, C., Eid, L., \& Ferrario, V.F. (2000). Sensorial afferents and center of foot pressure in blind and sighted adults. Journal of Visual Impairment and Blind. 94(2), 97- 107.

Shumway-Cook, A., \& Woollacott, M.H. (2003)

Motor Control: Theory and Practical applications. 2a ed. Sao Paulo: Manole, 153-78.

Shumway-Cook, A., Gruber, W., Baldwin, M., \& Liao, S. (1997). The effect of multidimensional exercises on balance, mobility, and fall risk in community dwelling older adults. Physical Therapy, 77, 46-57.

Studenski, S., Duncan, P. W., Chandler, J., Samsa, G., Prescott, B., Hogue, C., \& Bearon, L.B. (1994). Predicting falls: The role of mobility and nonphysical factors. Journal of American Geriatrics Society, 42, 297-304

Volman, M. J., Visser, J. J., \& Lensvelt-Mulders, G. J. (2007). Functional status in 5 to 7 -year-old children with Down syndrome in relation to motor ability and performance mental ability. Disability Rehabilitation, 29, 25-3.

Tomomitsu, M. S. V., Castilho, A., Morimoto, E., Bobbio, T., \& Greve, J. M. D. (2013). Static and dynamic postural control in low-vision and normal - vision adults. Clinics, 13(4), 517-521.

Topper, A. K., Maki, B. E., \& Holliday, P. J. (1993). Are activity-based assessments of balance and gait in the elderly predictive of risk of falling and or type of fall? Journal of American Geriatric Society, 41, 479-487

Vuillerme, N., Marin, L., \& Debu, B. (2001). Assessment of static postural control in teenagers with Down syndrome. Adapted Physical Activity Quarterly, 18, 417-433. 